\title{
Corporations' and Job Seekers' Using Intention and WOM (Word-of-Mouth) of NCS-based Job Matching System
}

\author{
Sunggwang Jung ${ }^{1, *}$, Jae Hyung Cho ${ }^{2}$, IL-Woon Kim ${ }^{3}$ \\ ${ }^{1}$ Entrepreneurship Education Center, Busan University of Foreign Studies, South Korea \\ ${ }^{2}$ Faculty of Global Business, Busan University of Foreign Studies, South Korea \\ ${ }^{3}$ Institute for Global Business, The University of Akron, USA
}

Received August 21, 2019; Revised September 19, 2019; Accepted September 26, 2019

Copyright@2019 by authors, all rights reserved. Authors agree that this article remains permanently open access under the terms of the Creative Commons Attribution License 4.0 International License

\begin{abstract}
This study designed a job matching system based on the National Competence Standard (NCS). In other words, we proposed an algorithm that can optimize the matching in employment in the $\mathrm{n}^{*} \mathrm{~m}$ situation. We set performance expectancy, effort expectancy, social influence, and facilitating conditions as the attributes of the NCS-based job matching system. Moreover, we tried to examine the relationship between NCS-based job matching service attributes, using intention and word-of-mouth (WOM). In addition, this study analyzed how the relationship between NCS-based job matching system service attributes and NCS-based job matching system using intention changes according to the type of service user (corporations, job seekers). The major results of this study are as follows. First, NCS-based job matching system attributes have a significant effect on using intention. Second, it was found that the intention to use the NCS-based job matching system had a positive effect on WOM. Third, NCS-based job matching system attributes on using intention differed depending on the type of service user (corporations, job seekers).
\end{abstract}

Keywords NCS Based Job Matching System, Performance Expectancy, Effort Expectancy, Social Influence, Facilitating Conditions, UTAUT, Using Intention, WOM, Corporations, Job Seekers

\section{Introduction}

The reasons for the unemployment of young people in Korea are being analyzed in diverse ways in terms of supply and demand [1]. To realize a competence-based society, the government established the National
Competence Standard (NCS), which systematized the knowledge, skills, and expertise required for job performance in the industrial fields. Also, public institutions have started to carry out a variety of policies, such as a work-study dual pursuit system and lifelong learning universities, to introduce and expand NCS-based human resources employment. NCS has standardized the job competencies required by corporations, and there is a continuing demand for the development and application of the NCS-based curriculum at universities [2].

The NCS-based employment framework proposed in this study starts with the problem of matching $\mathrm{N}$ students (job seekers) with $\mathrm{M}$ corporations, which is regarded as an assignment problem. In other words, soft matching, which shows associated research results even if only some conditions are met, is required instead of hard matching, which shows the search results when the matching conditions between job seekers and job openings in corporations are completely matched[3]. In this study, we developed an assignment algorithm for job matching and designed a job seeking and job opening system that can be used in universities. Therefore, we proposed an NCS-based job matching system that can be used in universities and analyzed the users' acceptance intention accordingly.

In this study, based on the argument of Venkatesh et al. [4], we set performance expectancy, effort expectancy, social influence, and facilitating conditions as the attributes of the NCS-based job matching system. Moreover, we tried to examine the relationship between the NCS-based job matching service attributes (performance expectancy, effort expectancy, social influence, and facilitating conditions) and using intention of the NCS-based job matching system. Also, this study analyzed the relationship between the using intention and 
WOM of the NCS-based job matching system.

In the present job seeking and job opening service market, service users can be largely divided into corporations and job seekers. This study presumed that the NCS-based job matching service attributes perceived by corporations and job seekers vary because they each have different interests and requirements. Therefore, this study also analyzed how the relationship between the NCS-based job matching system service attributes and the NCS-based job matching system using intention changes according to the type of service user (corporations, job seekers).

\section{Conceptual Framework and Hypotheses}

\subsection{NCS-based Job Matching System}

The NCS Learning Module is a teaching and learning tool designed to enable training and education institutes to teach NCS competence units, and it is based on the job skills required by the industries. In particular, as content strengthening the connection between specialized subjects and the NCS was proposed for the specialized school curriculum revised in 2015, the utilization rate of the NCS Learning Module is expected to increase.

This study designed the job matching system based on the NCS. In other words, we proposed an algorithm that can optimize the matching in employment in the $n^{*} m$ situation. We also focused on developing functions to be used easily in universities and corporations and tried to provide not only one optimal alternative but also many other alternatives. The optimal alternative here is a recommendation system based on the NCS evaluation index that can match the job seekers in the order that they are optimized for the jobs required by the corporations.

Therefore, this study considered the following aspects for efficient matching activities. First, students should be able to express their knowledge and the activities they carried out at their university clearly in their resume and self-introduction. Second, they should express the various qualifications they acquired during their university life as their basic job competence. Third, because different students have different job expectations and competencies, customized employment information and services should be provided to each student. This applies to their annual salary and working area, as well as various individual factors that may be considered later. Fourth, hard matching, which shows search results when these various matching factors are perfectly matched, leads to tremendous search costs for both the corporations and the job seekers. Therefore, search results with high user satisfaction should be derived by meeting some matching factors or using input information. For this, we defined matching factors and evaluation criteria for job matching algorithms in this study as shown in Table 1. Also, the users (corporations and job seekers) could indicate the importance (1-5 points) of their search conditions on all matching factors. Through this, it was possible to reflect the matching factors of high importance in user satisfaction.

Table 1. Job matching factors and evaluation

\begin{tabular}{|c|c|c|}
\hline Category & $\begin{array}{l}\text { Matching } \\
\text { Factors }\end{array}$ & Matching Evaluation Criteria \\
\hline \multirow{3}{*}{$\begin{array}{c}\text { NCS } \\
\text { Competencies }\end{array}$} & $\begin{array}{c}\text { Major at } \\
\text { university }\end{array}$ & $\begin{array}{c}\text { When there is a match: } \\
\text { - Weight }(1.2) * \text { GPA * Preference }(\mathrm{H} / \mathrm{M} / \mathrm{L})\end{array}$ \\
\hline & $\begin{array}{l}\text { Extra- } \\
\text { curricular } \\
\text { activities }\end{array}$ & $\begin{array}{c}\text { When there is a match: } \\
\text { - Weight (1.0)* Duration (Months) } * \text { Preference (H/M/L) }\end{array}$ \\
\hline & Competencies & $\begin{array}{l}\text { When there is a match } \\
\text { - Weight }(0.7) * \text { NCS-based competency points * Preference }(\mathrm{H} / \mathrm{M} / \mathrm{L})\end{array}$ \\
\hline $\begin{array}{l}\text { Individual } \\
\text { Preferences }\end{array}$ & Salary & $\begin{array}{c}\text { Difference in desired salary between the job seeker vs company } \\
\text { - High: }<5,000,000 \text { won* } \\
\text { - Medium: }<10,000,000 \text { won } \\
\text { - Low: }<20,000,000 \text { won }\end{array}$ \\
\hline
\end{tabular}




\subsection{Design of Job Matching Search System}

The purpose of the job matching search system is to provide optimal candidates (job seekers) to corporations by accurately collecting and analyzing their requirements for job openings. If we can accurately grasp the job opening requirements of corporations, these requirements can be used to direct university education. Also, universities can accurately identify and develop necessary competencies in talented students whom they want to educate. For this purpose, we designed the framework of this search system as shown in Figure 1.

This framework largely consists of three components. The first is the database in which the information on job seekers (students) and job openings of corporations is stored. The second is the search engine that can be used to search for job seekers desired by corporations. Corporations may search for the job seekers directly, but, in general, university officials search for them when requested by the corporations. Using this search engine, one can select the job and competencies required by the corporations and input the importance (1-5 points) of the job and competencies. Third, it consists of a rule that evaluates the optimal candidates through a Multi-Attribute Decision Making (MADM) algorithm by comparing and analyzing the value of the job and competencies required by the corporations and the value of the competencies of job seekers (students)[5].

To facilitate the understanding of this search system, a user interface was designed, as shown in Figure 2. The interface shows the details of matching factors and evaluation criteria for the job matching algorithm in Table 1. The major conformity, which is a matching factor, matches the department and required jobs in the interface. Activity conformity and basic job competence are matched according to the degree of conformity between the quantitative score (1-5 points) entered through the required competences and the words found in the requirement.

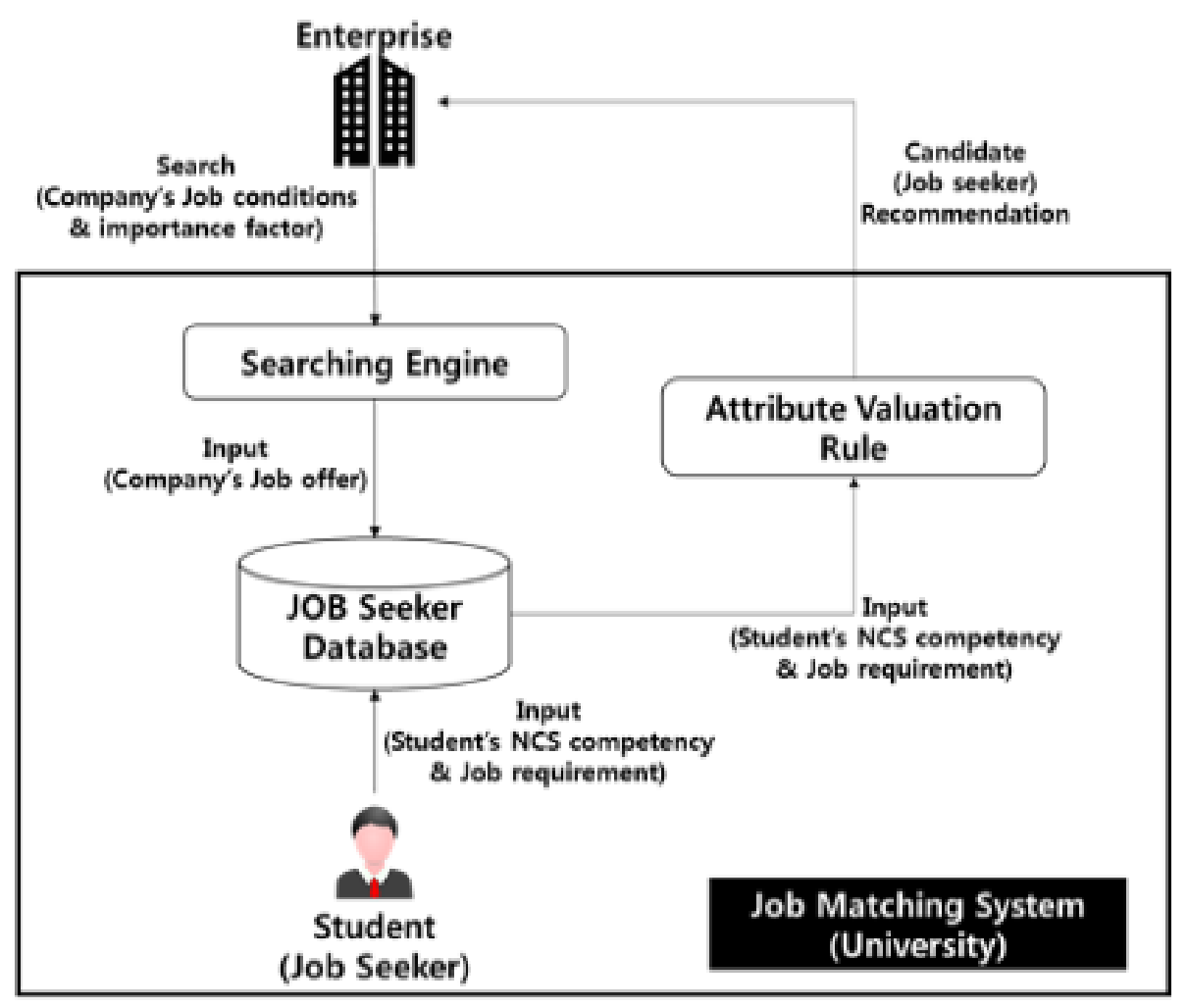

Figure 1. The framework of the job matching search system 


\section{Job Matching System}

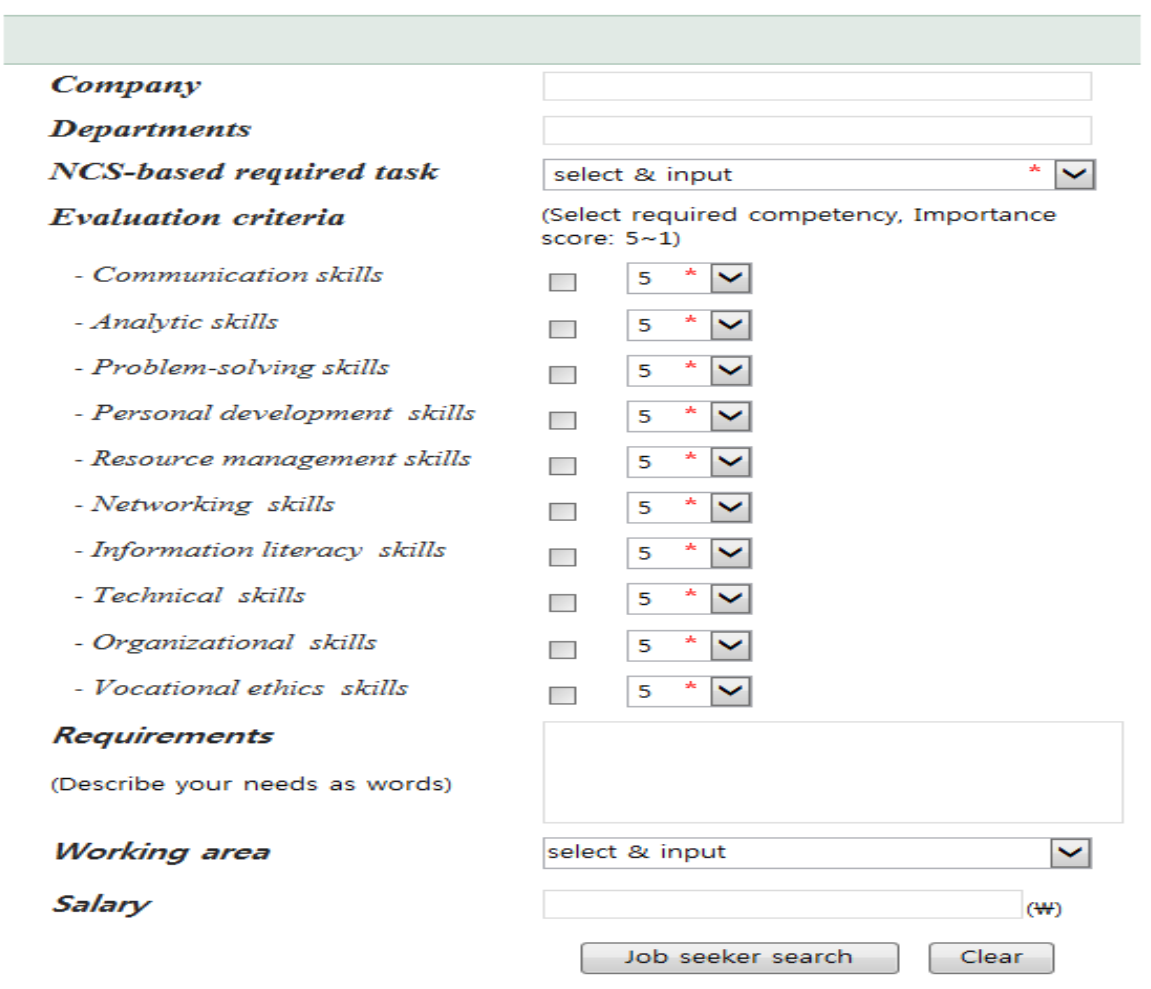

Figure 2. The interface of the job matching search system

\subsection{Unified Theory of Acceptance and Use of Technology (UTAUT)}

The UTAUT model was derived from the theory of reasoned action based on social psychology. The technology acceptance model was developed from the viewpoint that technology acceptance is more influenced by the characteristics of the information system than individual beliefs. However, it has limitations, in that it cannot identify the detailed variables, and it is difficult to analyze the interrelationships in the information technology (IT) environment [6].

Venkatesh et al. [4] identified these limitations and suggested that the topic be approached from an integrated perspective to predict the effects of technology acceptance effectively. Therefore, the UTAUT model, which is an integrated technology acceptance model, was proposed by integrating seven theories and models (i.e., TRA, TAM, MM, TPB, MPCU, IDT, and SCT) related to technology acceptance [7].

In the UTAUT, four key concepts-performance expectancy, effort expectancy, social influence, and facilitating conditions - are used to determine using intention and use behavior. Effort expectancy is defined as a degree of recognition that it is easy to use new technology. Performance expectancy is defined as the degree of personal belief that using new technology will help achieve the performance of the task or benefit users [8]. Social influence is defined as the degree of belief that one should accept and utilize new technologies when judged by other influential people. Facilitating conditions refers to the degree of belief that one has the organizational or technical foundation necessary for utilizing new technologies. The following hypotheses are presented based on this previous study.

H1: Effort expectancy for the NCS-based job matching system will positively influence the intention to use the NCS-based job matching system.

H2: Performance expectancy for the NCS-based job matching system will positively influence the intention to use the NCS-based job matching system.

H3: Social influence for the NCS-based job matching system will positively influence the intention to use the NCS-based job matching system.

H4: Facilitating conditions for the NCS-based job matching system will positively influence the intention to use the NCS-based job matching system.

\subsection{Relationship between Using Intention and Word-of-Mouth (WOM)}

Davis et al. [9] defined using intention as the intensity of intent to perform a particular act. Using intention is the intention to use IT, and, in the initial stage of IT introduction, user behavior can be indirectly measured by intention rather than by actual use. Other scholars defined WOM as a way to provide advertisements for perceived 
brands, products, and services provided by a corporation to others through person-to-person communication [10]. The following hypothesis is presented based on this previous study.

H5: The intention to use the NCS-based job matching system will positively influence WOM intention for the NCS-based job matching system.

\subsection{Service User Type (Corporations, Job Seekers)}

There are two main types of service users who utilize the domestic job market. The first type is the corporations. The corporations want the people who can provide them practical benefits by demonstrating the capabilities they desire. The second type is job seekers. The job seekers receive a certain amount of salary by providing the competencies required by the corporations [11].

The biggest difference between these two groups is that corporations provide remuneration to job seekers, and job seekers receive remuneration from corporations. In terms of competencies, however, corporations receive competencies from job seekers, and the job seekers provide competencies to corporations. In short, corporations and job seekers are in conflict with each other [12].

Therefore, this study expects that the relationship between the NCS-based job matching system service attributes and the NCS-based job matching system using intention will vary depending on the type of service user (corporations, job seekers) being studied. Based on this argument, the following hypotheses are presented.

H6: The effect of the NCS-based job matching system service attributes on using intention will vary according to the type of service user.

H6-1: The effect of effort expectancy on using intention will vary depending on the type of service user (corporations, job seekers).

H6-2: The effect of performance expectancy on using intention will vary depending on the type of service user (corporations, job seekers).

H6-3: The effect of social influence on using intention will vary depending on the type of service user (corporations, job seekers).

H6-4: The effect of facilitating conditions on using intention will vary depending on the type of service user (corporations, job seekers).

\section{Research Model Design}

\subsection{Research Model}

To achieve the research purpose, the research model was designed to analyze the structured relationship between the NCS-based job matching system service attributes using intention and WOM. Along with this, this study examined the moderate effect of service users (corporations, job seekers).

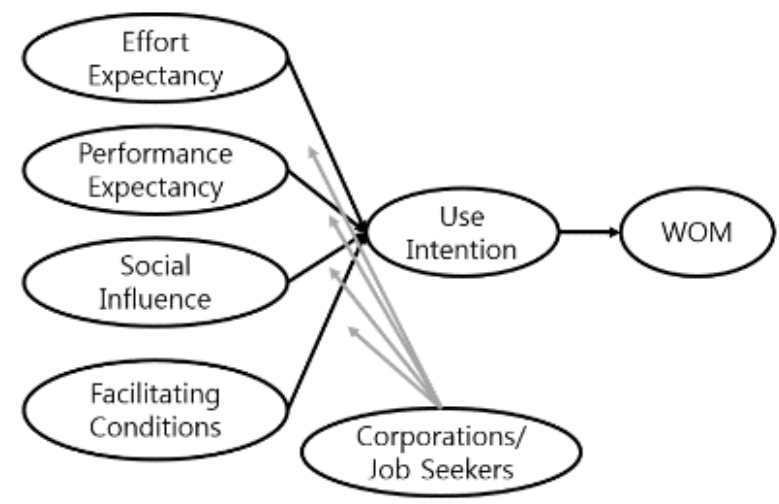

Figure 3. Framework

\section{Empirical Analysis}

\subsection{Data Collection}

The questionnaires were divided into surveys for corporations and surveys for job seekers. In addition, for the measurement items for corporations and job seekers, questionnaire sheets composed of the same measurement items were used.

The questionnaire survey was conducted from March 16, 2019 to March 21, 2019, targeting respondents in their 20 s to 70 s from various occupations. The respondents were selected through the following measurement item: "Do you know about the NSC?" Then, we explained the NCS-based job matching system developed in this study to them and had them answer the questionnaire.

A total of 300 questionnaire sheets were distributed, and all of them were collected. However, only 287 sheets were used in this study, as 13 sheets were deemed inappropriate. Respondents were provided with small gifts in exchange for their participation. Among a total of 287 respondents, the number of corporations was 139 , and the number of job seekers was 148 .

In this study, NCS-based job matching system service attributes was measured using scale developed by Venkatesh et al. [4]. Using intention was measured also using scale developed by Davis et al. [9]. Lastly WOM was measured using scale developed by Chu and Kim [13]. Appendix 1 presents item of NCS-based job matching system service attributes, using intention, WOM for each measure.

\subsection{Verification of Reliability and Validity}

As a result, Cronbach's $\alpha$ value for the six research concepts was over 0.9 , and it was judged that the reliability of the measurement tool was established. Also, 
exploratory factor analysis was conducted to confirm the constructs of measurement items. The exploratory factor analysis was carried out using the Varimax rotation method, and the factor loadings were found to be 0.6 or higher only for the factors with an eigenvalue of 2.4 or higher through the factor analysis process.

Confirmatory factor analysis (CFA) was also conducted. The overall model fit was found to be $X^{2}=281.18(\mathrm{df}=237$, $\mathrm{p}=0.002), \quad \mathrm{GFI}=0.924, \quad$ AGFI $=0.904, \quad \mathrm{CFI}=0.995$, $\mathrm{NFI}=0.968$, TLI $=0.994$ and RMSEA $=0.026$. Also, the t-values for factor loadings of constructs were found to be 24.0 or higher, which indicates that the measurement items for the NCS-based job matching system service attributes using intention and WOM intention were valid.

To evaluate whether the measurement items were representative for the study unit, the average variance extraction (AVE) and the conceptual reliability were analyzed in this study. The reliability of the study unit exceeded the recommended standard of .80, and the AVE exceeded the recommended standard of .50. Therefore, the items of this study were found to have the representativeness of the research units.

Lastly, in order to check whether there was a clear distinction between the two similar research concepts, judgment validity was verified. The judgment validity is identified by determining whether each AVE exceeds the square $\left(\varnothing^{2}\right)$ of the correlation coefficient between concepts [14]. As a result of the verification of judgment validity of this study, the AVE value was higher than the square $\left(\emptyset^{2}\right)$ of the correlation coefficient, so the judgment validity of this study was confirmed. Through these results, the internal validity and judgment validity of this study were proven.

\subsection{Research Hypothesis Testing}

To conduct the research hypothesis testing in this study, statistical analysis was performed using AMOS 18.0 after setting the structural equation model. The results of the empirical analysis are as follows. As a result of examining H1, H2, H3, H4, H5, the path coefficient value was statistically supported.

Table 2. Result of Analysis

\begin{tabular}{|c|c|c|c|c|}
\hline \multicolumn{2}{|r|}{ Hypothesis } & Estimate & S.E. & C.R. \\
\hline $\mathrm{H} 1$ & $\begin{array}{l}\text { Effort Expectancy } \\
\rightarrow \text { Using Intention }\end{array}$ & $0.136^{* * *}$ & 0.041 & 3.303 \\
\hline $\mathrm{H} 2$ & $\begin{array}{l}\text { Performance Expectancy } \\
\quad \rightarrow \text { Using Intention }\end{array}$ & $0.323^{* * *}$ & 0.034 & 9.401 \\
\hline H3 & $\begin{array}{l}\text { Social Influence } \\
\rightarrow \text { Using Intention }\end{array}$ & $0.277^{* * *}$ & 0.042 & 6.543 \\
\hline $\mathrm{H} 4$ & $\begin{array}{l}\text { Facilitating Conditions } \\
\rightarrow \text { Using Intention }\end{array}$ & $0.268^{* * *}$ & 0.039 & 6.804 \\
\hline $\mathrm{H} 5$ & Using Intention $\rightarrow$ WOM & $0.963^{* * *}$ & 0.063 & 15.196 \\
\hline \multicolumn{5}{|c|}{$\begin{array}{c}\mathrm{x}^{2}=298.57(\mathrm{df}=241, \mathrm{p}=0.007), \mathrm{GFI}=.920, \mathrm{AGFI}=.900, \mathrm{CFI}=.993 \\
\mathrm{NFI}=.966, \mathrm{TLI}=.992, \mathrm{RMSEA}=.029\end{array}$} \\
\hline
\end{tabular}

\subsection{Moderate Effect of Service User Type in the Relationship between the NCS-based Job Matching System Service Attributes and Using Intention}

\subsubsection{Hypothesis Test for the Moderate Effect of Service User Type in the Relationship between the NCS-based Job Matching System Service Attributes and Using Intention}

This study conducted the $\mathrm{x}^{2}$ difference test using AMOS 18.0 to test the moderate effect of service user type (corporations, job seekers).

First, as a result of testing H6-1, the difference between the two models was found to be significant $\left(\Delta x^{2}=33.298\right.$ $\left.<x^{2} .05(1)=3.84\right)$. Next, as a result of testing H6-2, the difference between the two models was found to be significant $\left(\Delta \mathrm{x}^{2}=16.92<\mathrm{x}^{2} .05(1)=.3 .84\right)$. Third, as a result of testing H6-3, the difference between the two models was found to be significant $\left(\Delta \mathrm{x}^{2}=9.25<\right.$ $\left.\mathrm{x}^{2} .05(1)=.3 .84\right)$. Lastly, as a result of testing H6-4, the difference between the two models was found to be significant $\left(\Delta \mathrm{x}^{2}=14.76<\mathrm{x}^{2} .05(1)=.3 .84\right)$. As a result, it was confirmed that the moderate effect of service user type (corporations, job seekers) occurs in the relationship between facilitating conditions and using intention. Also, the path coefficient value of job seekers was significantly higher than that of corporations. Therefore, H6-4 was supported.

As a result, it was confirmed that the moderate effect according to service user type (corporations, job seekers) occurs in the relationship between effort expectancy, performance expectancy, social influence, facilitating conditions, and using intention. In H1, the path coefficient value of job seekers was not significant, while that of corporations was significant. However, in H2, H3, and H4, the path coefficient value of job seekers was significantly higher than that of corporations. Therefore, H6-1, H6-2, H6-3, and H6-4 were supported.

\section{Conclusions}

The major results of this study are as follows. First, NCS-based job matching system attributes have a significant effect on using intention. Also, the effect of effort expectancy was highest, followed by social influence, facilitating conditions, and performance expectancy. Second, it was found that the intention to use the NCS-based job matching system had a positive effect on WOM. Third, it was found that the effect of the NCS-based job matching system attributes on using intention differed depending on the type of service user (corporations, job seekers). In particular, the effect of effort expectancy among the NCS-based job matching system attributes on using intention was higher in job seekers than in corporations. 
For the job matching system to be applied successfully to the job market, the following policy is necessary. First, the clearer and richer the job seeker information and the requirements of the corporation are, the more accurate job matching is. Therefore, the data required by this system should be quantitative and measurable. To that end, the government should first come up with a policy to protect personal information. Also, job seekers and corporations should recognize and approve their information in advance so that it can be used for job matching. Second, the operation of the job matching system is suitable for third-party professionals who connect job seekers with corporations. For example, it could be a professional entity, such as LinkedIn, or a public institution (such as a college). Third, the job matching system should analyze the job seeker's career and the requirements of the corporation, and then score matching results to show ranking information. This should make it easier for job seekers, corporations, or third parties to identify the appropriate candidate rankings for the enterprise. The more points a person gets, the more his or her major and career matches the company's requirements. High ranking candidates will be recommended to the company and opportunities such as interviews will be given priority for those candidates. However, the effects of performance expectancy, social influence, and facilitating conditions on using intention were higher in corporations than in job seekers.

\section{Acknowledgement}

This work was supported by the Ministry of Education of the Republic of Korea and the National Research Foundation of Korea (NRF-2017S1A5A2A03068148).

\section{Appendix: Definition of Variables and Questionnaire}

Effort expectancy: The degree of think that it will be easy to use the new technology.

(1) I seem to adapt easily to this system.

(2) I am not difficult to use this system.

(3) I don't think difficult to learn this system.

(4) I can easily to operate this system.

Performance expectancy: The degree of the believe that using new technology will help achieve the job's performance.

(1) I think this system will be more useful than other job matching program.

(2) I think this system will improve the efficiency of job matching.

(3) I think this system will improve the convenience of job matching.
(4) I think this system will be processed faster than other job matching systems.

Social influence: Judging from the position of the neighbors, the degree of believe that one should accept and use the new technologies.

(1) Someone who has an influence on me (e.g., senior workers, major clients) think that I will use this system naturally.

(2) Someone who is important to me (e.g., school seniors, family) think that I will use this system naturally.

(3) I think that my neighbors will help me with using this system.

(4) I think that I will discuss about this system with my colleagues.

Facilitating condition: The degree of believe that personal has the organizational or technical foundation necessary to utilize new technologies.

(1) I have the conditions and equipment necessary to using this system.

(2) I have the necessary knowledge to use this system.

(3) When I use this system, I can get necessary help from an expert.

(4) I think that this system fits my lifestyle.

Use intention: The degree of intent to perform the particular act.

(1) I will use this system soon.

(2) I would like to use job matching services in this system.

(3) I will use this system more than other job matching service.

(4) I will use this system consistently and diversely.

WOM(Word Of Mouth): The act of recommending to others using communication.

(1) I will recommend this system to my acquaintances.

(2) I would like to share the experience of this system with others.

(3) I will tell my acquaintances about the advantages of this system.

(4) I will recommend to others to use this system.

※ This questionnaire asked 'NCS-based job matching system' as 'this system'.

\section{REFERENCES}

[1] Lee, M., Oi-yeung Lam, B., Ju, E., Dean, J., "Part-Time Employment and Problem Behaviors: Evidence from Adolescents in South Korea," Journal of research on adolescence, Vol.27, No.1, pp. 88-104, 2017.

[2] Yang, Y. K., Chung, W. H., "A Study on the Reorganization of the Liberal Arts Curriculum, based on the NCS Professional Basic Ability and the Industry 
Demand for Liberal Arts Education -Focusing on the Case of D University," Korean Journal of General Education, Vol.9, No.2, pp. 35-65, 2015.

[3] Park, S., Cho, J., Hyunjoong Jun, Kim, J., Ryu, J., "Development of Job Matching Function," Quarterly Journal of Labor Policy, Vol.12, No.3, pp. 25-51, 2012.

[4] Venkatesh, V., Morris, M. G., Davis, G. B., Davis, F. D., "User acceptance of information technology: Toward a unified view," MIS quarterly, Vol.27, No 3, pp. 425-78, 2003.

[5] Dyer, J., "MAUT—Multiattribute utility theory. In Multiple criteria decision analysis: state of the art surveys," Springer, New York, NY, pp. 265-292, 2005.

[6] Agarwal, R., Karahanna, E., "Time Flies when you're having Fun: Cognitive Absorption and Beliefs about Information Technology Usage," MIS quarterly, Vol.24, No.4, pp. 665-94, 2000.

[7] Goldsmith, R. E., Hofacker, C. F., "Measuring Consumer Innovativeness," Journal of The Academy of Marketing Science, Vol.19, No.3, pp. 209-21, 1991.

[8] Rogers, E. M., "Diffusion of Preventive Innovations," Addictive Behaviors, Vol.27, No.6, pp. 989-93, 2002.

[9] Davis, F. D., Bagozzi, R. P., Warshaw, P. R., "Extrinsic and Intrinsic Motivation to Use Computers in the Workplace1," Journal of Applied Social Psychology, Vol.22, No.14, pp. 1111-32, 1992.

[10] Harrison-Walker, L. J., "The Measurement of Word-of-Mouth Communication and An Investigation of Service Quality and Customer Commitment as Potential Antecedents," Journal of Service Research, Vol.4, No.1, pp. 60-75, 2001.

[11] Mavromaras, K., Sloane, P., \& Wei, Z., "The role of education pathways in the relationship between job mismatch, wages and job satisfaction: a panel estimation approach,” Education Economics, Vol.20, No.3, pp. 303-321, 2012.

[12] Lee, Y., \& Sabharwal, M., "Education-job match, salary, and job satisfaction across the public, non-profit, and for-profit sectors: Survey of recent college graduates," Public Management Review, Vol.18, No.1, pp. 40-64, 2016.

[13] Chu, S. C., Kim, Y., "Determinants of consumer engagement in electronic word-of-mouth (eWOM) in social networking sites," International journal of Advertising, Vol.30, No.1, pp. 47-75. 2011.

[14] Fornell, C., Larcker, D. F., "Evaluating Structural Equation Models with Unobservable Variables and Measurement Error," Journal of Marketing Research, Vol.18, No.1, pp. 39-50, 1981. 